\title{
The CoLaus study: a population-based study to investigate the epidemiology and genetic determinants of cardiovascular risk factors and metabolic syndrome
}

\author{
Mathieu Firmann ${ }^{\dagger 1}$, Vladimir Mayor ${ }^{\dagger 1}$, Pedro Marques Vidal ${ }^{2}$, \\ Murielle Bochud², Alain Pécoud ${ }^{3}$, Daniel Hayoz ${ }^{4}$, Fred Paccaud ${ }^{2}$, \\ Martin Preisig5, Kijoung S Song ${ }^{6}$, Xin Yuan $^{6}$, Theodore M Danoff7, \\ Heide A Stirnadel ${ }^{8}$, Dawn Waterworth ${ }^{6}$, Vincent Mooser ${ }^{6}$, Gérard Waeber $^{1}$ \\ and Peter Vollenweider*1
}

\begin{abstract}
Address: ${ }^{1}$ Department of Medicine, Internal Medicine, CHUV, Lausanne, Switzerland, ${ }^{2}$ Institute of Social and Preventive Medicine (IUMSP), University of Lausanne, Switzerland, ${ }^{3}$ Outpatient Clinic, University of Lausanne, Switzerland, ${ }^{4}$ Department of Medicine, Angiology, CHUV, Lausanne, Switzerland, ${ }^{5}$ Department of Psychiatry, CHUV, Lausanne, Switzerland, ${ }^{6}$ Medical Genetics/Clinical Pharmacology and Discovery Medicine, GlaxoSmithKline, Philadelphia PA, USA, ${ }^{7}$ Center of Excellence for Drug Discovery CV, GlaxoSmithKline, Philadelphia PA, USA and 8Worldwide Epidemiology, GlaxoSmithKline, Harlow, UK

Email: Mathieu Firmann - Mathieu.Firmann@chuv.ch; Vladimir Mayor - Vladimir.Mayor@chuv.ch; Pedro Marques Vidal - PedroManuel.Marques-Vidal@chuv.ch; Murielle Bochud - Murielle.Bochud@chuv.ch; Alain Pécoud - Alain.Pecoud@hospvd.ch; Daniel Hayoz - hayoz@hopcantfr.ch; Fred Paccaud - ed.Paccaud@chuv.ch; Martin Preisig - Martin.Preisig@chuv.ch; Kijoung S Song - kijoung.2.song@gsk.com; Xin Yuan - xin.2.yuan@gsk.com; Theodore M Danoff - theodore.m.danoff@gsk.com; Heide A Stirnadel - heide.a.stirnadel@gsk.com; Dawn Waterworth - dawn.m.waterworth@gsk.com;

Vincent Mooser - vincent.2.mooser@gsk.com; Gérard Waeber - Gerard.Waeber@chuv.ch; Peter Vollenweider* - Peter.Vollenweider@chuv.ch

* Corresponding author †Equal contributors
\end{abstract}

\section{Published: 17 March 2008}

BMC Cardiovascular Disorders 2008, 8:6 doi:10.1 186/147|-226I-8-6

This article is available from: http://www.biomedcentral.com/|47I-226I/8/6

(C) 2008 Firmann et al; licensee BioMed Central Ltd.

This is an Open Access article distributed under the terms of the Creative Commons Attribution License (http://creativecommons.org/licenses/by/2.0), which permits unrestricted use, distribution, and reproduction in any medium, provided the original work is properly cited.
Received: 12 November 2007

Accepted: 17 March 2008

\begin{abstract}
Background: Cardiovascular diseases and their associated risk factors remain the main cause of mortality in western societies. In order to assess the prevalence of cardiovascular risk factors (CVRFs) in the Caucasian population of Lausanne, Switzerland, we conducted a population-based study (Colaus Study). A secondary aim of the CoLaus study will be to determine new genetic determinants associated with CVRFs.

Methods: Single-center, cross-sectional study including a random sample of 6,188 extensively phenotyped Caucasian subjects (3,25I women and 2,937 men) aged 35 to 75 years living in Lausanne, and genotyped using the $500 \mathrm{~K}$ Affymetrix chip technology.

Results: Obesity (body mass index $\geq 30 \mathrm{~kg} / \mathrm{m}^{2}$ ), smoking, hypertension (blood pressure $\geq 140 / 90 \mathrm{mmHg}$ and/or treatment), dyslipidemia (high LDL-cholesterol and/or low HDL-cholesterol and/or high triglyceride levels) and diabetes (fasting plasma glucose $\geq 7 \mathrm{mmol} / \mathrm{l}$ and/or treatment) were present in 947 (I5.7\%), I673 (27.0\%), 2268 (36.7\%), 2 II 3 (34.2\%) and 407 (6.6\%) of the participants, respectively, and the prevalence was higher in men than in women. In both genders, the prevalence of obesity, hypertension and diabetes increased with age.

Conclusion: The prevalence of major CVRFs is high in the Lausanne population in particular in men. We anticipate that given its size, the depth of the phenotypic analysis and the availability of dense genome-wide genetic data, the CoLaus Study will be a unique resource to investigate not only the epidemiology of isolated, or aggregated CVRFs like the metabolic syndrome, but can also serve as a discovery set, as well as replication set, to identify novel genes associated with these conditions.
\end{abstract}




\section{Background}

Cardiovascular diseases (CVD) are the major cause of early mortality and morbidity in industrialized countries [1]. The prevalence of classical cardiovascular (CV) risk factors (CVRFs) such as hypertension, dyslipidemia, obesity and diabetes varies widely between different countries, and shows some important secular trends

Hypertension, obesity, dyslipidemia and diabetes mellitus have an important genetic component $[2,3]$. These conditions, however, are genetically complex, and only a small fraction of these diseases are accounted for by Mendelian forms. The availability of large case-control genome-wide association studies has led to the identification of susceptibility genes for common conditions, with even modest effects. Population-based studies have additional advantages; they make it possible to perform association studies for any continuous phenotypic trait which has been properly monitored, as well as for categorical traits using extreme discordant case-control designs, as long as these conditions are sufficiently prevalent. In addition, they offer the opportunity to explore the genetic determinants of aggregated phenotypes such as the metabolic syndrome. Finally, this type of studies provide the opportunity to perform re-sequencing analysis on extremes of the distribution, and to identify rare genetic variants with a strong phenotypic effect [4]. The success of such studies relies on a large collection, detailed and standardized phenotypes, strong analytical capabilities, replication sets and extensive genotyping [5]. To harness the power of these technologies, we designed the CoLaus study. The major goals of the CoLaus Core study were to get a snap picture of the prevalence and severity of CVRFs in a particular population and to elucidate the molecular architecture of isolated CVRFs, as well as clusters of CVRFs like the metabolic syndrome. In this article, we present the protocol of the study as well as results for the prevalence of multiple cardiovascular risk factors the Lausanne population.

\section{Methods}

\section{Recruitment process and sample size}

The Study was approved by the Institutional Ethic's Committee of the University of Lausanne and recruitment took place in the city of Lausanne in Switzerland, a town of 117,161 inhabitants, of which 79,420 are of a Swiss nationality[6].

The complete list of the Lausanne inhabitants aged 35-75 years ( $\mathrm{n}=56,694$ in 2003) was provided by the population register of the city and served to sample the participants to the study. All subjects living in the city of Lausanne in 2003 for more than 90 days have their name included in this register. The register had information on age and gender but no information regarding ethnicity or country of origin.
Given the allele frequency of most SNPs on the Affymetrix chip and the genetic effect sizes expected for complex diseases (i.e. OR 1.3 and above), we chose to include 6000 individuals, so as to have enough power $(\sim 80 \%)$ to detect genetic associations for diseases with a prevalence of $\sim 15 \%$.

A simple, non-stratified random selection of 19,830 subjects, corresponding to $35 \%$ of the source population, was drawn using STATA v9.1 software (Stata Corp, College Station, USA), and a letter inviting the addressee to participate in the study was sent to these individuals.

Subjects who volunteered to participate were contacted by phone within 14 days by one of the staff members to set up an appointment. Subjects who didn't answer were sent a second invitation letter. If no answer was obtained, they were contacted by phone. Subjects were considered as non-participants if they refused to participate and as nonresponders if contact couldn't be made after two successive letters and three successive phone calls. Individuals who didn't live in Lausanne any longer, who were dead or who didn't meet the age criteria were considered as noneligible. Recruitment began in June 2003 and ended in May 2006.

The sampling procedure is summarized in Figure 1. Of the initial 19,830 subjects sampled, 54 subjects were considered as non-eligible before contact and 15,109 (76\%) responses were obtained. A total of 4667 subjects who did not respond were considered as non-responders. Among responders, $6,189(41 \%)$ subjects refused to participate in the study and $799(5 \%)$ were considered as non-eligible. Among the latter, 53\% moved to a different city, 32\% were out of the age range and $11 \%$ were reported to be deceased. The sample of 8,121 subjects who agreed to participate represented $41 \%$ of the initially sampled population, $54 \%$ of all responders and $57 \%$ of all eligible responders.

\section{Inclusion criteria}

The following inclusion criteria were applied: a) written informed consent; b) age 35-75 years and c) Caucasian origin. Caucasian origin was defined as having both parents and grandparents born in a restricted list of countries (available from the authors). No other exclusion criteria were applied. Since ethnicity could only be established during the clinic visit, some participants were assessed but were not included in the CoLaus study. Their data will be described elsewhere.

\section{Assessment process}

Participants were asked to attend the outpatient clinic at the Centre Hospitalier Universitaire Vaudois (CHUV) in the morning after an overnight fast. They had to take their medication as usual. Data were collected by trained field 


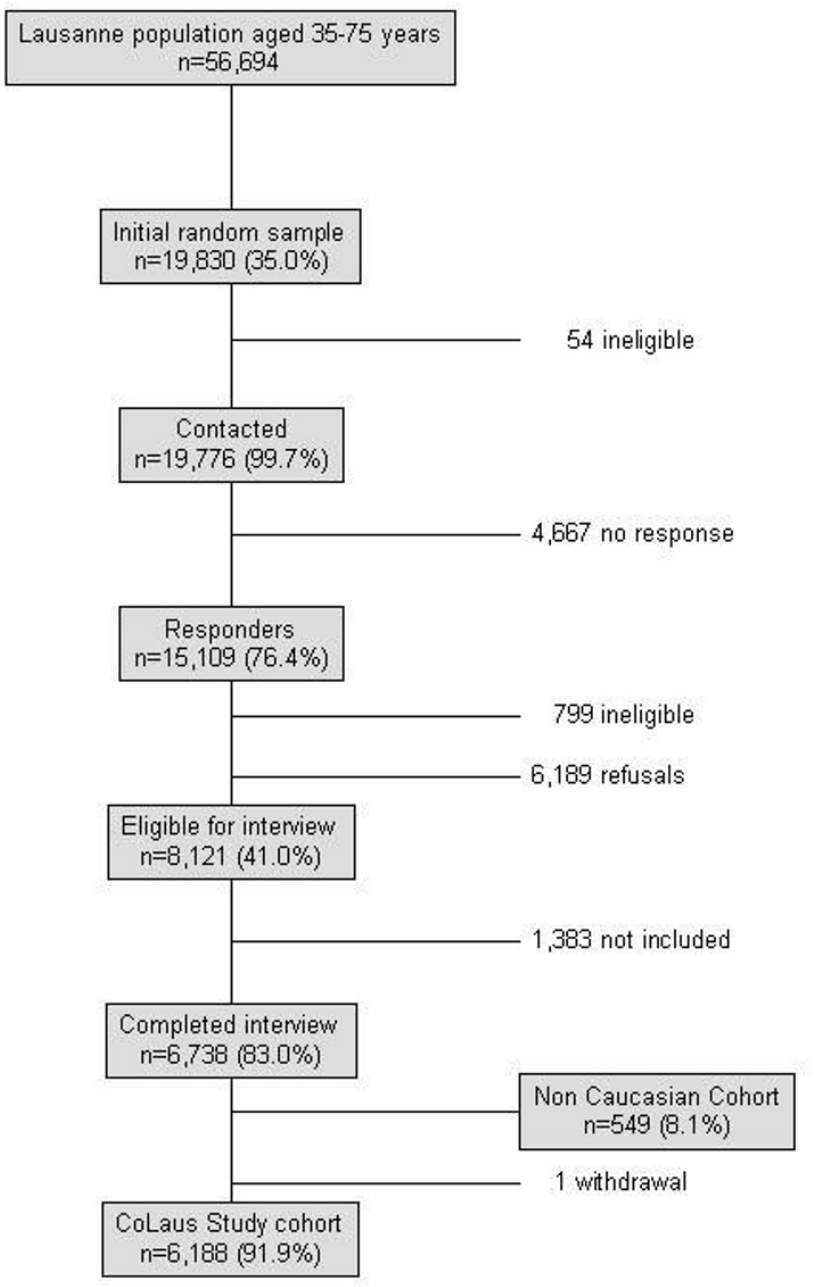

Figure I

Flow chart of the CoLaus Study.

interviewers in a single visit lasting about 60 minutes. Informed consent was obtained from participants upon their arrival at the study clinic. The first questionnaire mailed with the appointment's letter and completed by the participant prior to the morning visit was then quickly reviewed and a second questionnaire was applied by interview prior to clinical measurements and blood collection.

\section{Questionnaire data}

The first set of questionnaires recorded information on demographic data, socio-economic and marital status, and several lifestyle factors, namely tobacco, alcohol and caffeine consumption, physical activity and mood. Data on smoking included the previous and current smoking status as well as the amount of tobacco smoked (number of cigarettes, cigarillos, cigars or pipes), age of beginning and end (for former smokers). Similarly, data on alcohol consumption included the past and current drinking status as well as the number of alcoholic beverage units (wine, beer and spirits) consumed over the week preceding the interview. Caffeine consumption was assessed by the number of caffeine-containing beverages consumed per day. Personal history of overweight and/or obesity and birth weight were also collected. Finally, the 12-item General Health Questionnaire (GHQ12) [7] was applied in order to screen for the presence of non-psychotic psychiatric disorders.

The second questionnaire, administered during a face-toface meeting with the recruiter, focused on personal and family history of disease and CV risk factors. Subjects were asked which disease(s) they or their family had presented. When a positive answer was given, further information regarding age of occurrence and number of family members affected was collected. When appropriate, death of parents was recorded with age and cause of death. Regarding blood pressure (BP) status, subjects indicated if they had been diagnosed with hypertension and subsequently if they had been, or were being treated currently for this condition. BP levels before the beginning of treatment were sought for and the names of the anti-hypertensive drugs that had been prescribed were collected. In case the anti-hypertensive regimen had been modified, the duration and the reason for changing were also recorded. Personal medicines, including prescription and selfprescribed drugs, vitamin and mineral supplements, homeopathy or natural remedies were collected, together with their main indications. In women, further data regarding reproductive and obstetrical history, oral contraception and hormonal replacement therapy was collected. Finally, an additional frailty questionnaire (for subjects aged over 50 years) and the Mini-Mental State Evaluation (MMSE - for subjects aged over 65 years) were further administered [8].

\section{Clinical data}

Body weight and height were measured with participants standing without shoes in light indoor clothes. Body weight was measured in kilograms to the nearest $0.1 \mathrm{~kg}$ using a Seca ${ }^{\circledast}$ scale (Hamburg, Germany), which was calibrated regularly. Height was measured to the nearest 5 mm using a Seca ${ }^{\varpi}$ height gauge (Hamburg, Germany). Body mass index (BMI) was defined as weight/height ${ }^{2}$. Obesity was defined as $\mathrm{BMI} \geq 30 \mathrm{~kg} / \mathrm{m}^{2}$ and overweight as BMI $\geq 25 \mathrm{~kg} / \mathrm{m}^{2}$ and $<30 \mathrm{~kg} / \mathrm{m}^{2}$.

$\mathrm{BP}$ and heart rate were measured thrice on the left arm, with an appropriately sized cuff, after at least 10 minute rest in the seated position using an Omron $^{\circledast}$ HEM-907 automated oscillometric sphygmomanometer (Matsusaka, Japan) [9]. The average of the last two measurements was used for analyses. Hypertension was defined as a 
systolic BP $(\mathrm{SBP}) \geq 140 \mathrm{~mm} \mathrm{Hg}$ and/or a diastolic BP $(\mathrm{DBP}) \geq 90 \mathrm{~mm} \mathrm{Hg}$ during the visit and/or presence of anti-hypertensive drug treatment and was considered as known if the subject was aware of this condition.

In addition, waist and hip circumferences were measured as recommended [10] and fat and fat-free mass were assessed by electrical bioimpedance [11] using the Bodystat $^{\circledR} 1500$ analyzer (Isle of Man, British Isles). Finally, baldness and its age of onset were assessed in men using the Hamilton scale [12].

\section{Sub-studies}

In addition, sub-studies designed to assess the psychiatric characteristics of this population as well as functional CV measurements, were nested onto this study, and will be described separately.

\section{Biological data}

Venous blood samples $(50 \mathrm{ml})$ were drawn after an overnight fast, and most clinical chemistry assays were performed by the CHUV Clinical Laboratory on fresh blood samples whereas Pathway Diagnostics (Los Angeles, CA) measured adiponectin, leptin and insulin [See additional file 1]. Additional aliquots were stored at $-80^{\circ} \mathrm{C}$.

LDL-cholesterol was calculated with the Friedewald formula only if triglycerides $<4.6 \mathrm{mmol} / \mathrm{l}$. Low HDL cholesterol level was defined as $<1.0 \mathrm{mmol} / \mathrm{L}$; high $\mathrm{HDL}$ cholesterol as $\geq 1.6 \mathrm{mmol} / \mathrm{L}$; high $\mathrm{LDL}$ cholesterol was defined as $\geq 4.1 \mathrm{mmol} / \mathrm{L}$ and high triglyceride level was defined as $\geq 2.2 \mathrm{mmol} / \mathrm{L}$ [13]. In our analysis, dyslipidemia was defined as low HDL cholesterol and/or high triglyceride and/or LDL cholesterol $\geq 4.1 \mathrm{mmol} / \mathrm{L}$ or $\geq 2.6$ $\mathrm{mmol} / \mathrm{L}$ in presence of self-reported history of myocardial infarction, stroke, coronary artery disease or diabetes.

Diabetes was defined as fasting plasma glucose $\geq 7.0$ $\mathrm{mmol} / \mathrm{L}$ and/or presence of oral hypoglycaemic or insulin treatment. Type 2 diabetes mellitus (T2DM) was defined in case of diabetes without self-reported Type 1 DM. Diabetes was considered as known if the subject was aware of this condition. Impaired fasting glucose (IFG) was defined as fasting plasma glucose between 6.1 and 6.9 $\mathrm{mmol} / \mathrm{L}$ without anti-diabetic treatment [14].

A urine sample was collected for the assessment of creatinine and albumin and the albumin-to-creatinine ratio was calculated. Microalbuminuria was defined as a value of albumin-to-creatinine ratio above $30 \mathrm{mg} / \mathrm{g}$.

\section{Genotyping}

Nuclear DNA was extracted from whole blood for whole genome scan analysis and genotyping was performed using the Affimetrix 500 K SNP chip, as recommended by the manufacturer. Subjects consented for the genetic data to be used for the study of cardiovascular risk factors, and associated diseases including mood disorders.

\section{Data management, security and quality control}

Data were entered into a secured, internet-based database. The database was designed to confirm the validity of the identification codes, establish the completeness of the information keyed in and to perform basic data checks. All discrepancies were recorded in the case report form kept in a locked room. Each modification of the data was automatically recorded, including the identity of the investigator who made the modification, the date, the old and the new value.

Staff members were trained and certified before being involved actively in the study. Certification included ability to conduct interviews, to perform phlebotomy and to process blood samples, to accurately measure anthropometric and BP levels and to enter data into electronic databases. The accurateness of the data was checked by an external quality control organization (PRN, North Hampshire, United Kingdom).

Finally, the 'Laboratoire Central du CHUV' is ISO 9001 certified and is regularly checked by the "Centre Suisse de Contrôle de Qualité" (CSCQ - Swiss Centre for Quality Control).

\section{Power estimates and type I error rate}

Power calculations were done using the program Quanto v1.1 (James Gauderman, University of Southern California, USA) [15]. Power for unmatched case-control studies was estimated using an arbitrary allelic frequency ranging from 0.1 to 0.5 , an additive model, a disease prevalence of $50 \%$ and a type 1 error rate of $10^{-7}$, which was used as a correction for multiple testing taking into account 500'000 genetics markers. Curves were drawn for estimated genetic effect sizes (odds ratios) of 1.2 to 1.8 . To estimate power in a continuous trait analysis, SBP was used as a continuous outcome for independent subjects, with an additive model and a type 1 error rate of $10^{-7}$. Curves were drawn for various minor allele frequencies ( 0.1 to 0.5$)$. To minimize false positive results, the most significant genetic markers will be replicated in independent samples.

\section{Statistical analysis}

Statistical analyses were performed using Stata 9.1 (Stata Corp, College Station, USA). Results were expressed as mean \pm standard deviation (SD) or as number of subjects and (percentage). Data for age group 35-75 years and for the canton de Vaud were extracted from the MONICA population surveys and used to assess trends [16]. Age at sampling was used for comparisons between the initial 
population, the random sample and the CoLaus study population, whereas age at examination was used to describe the CoLaus Study group characteristics. Comparisons were performed using Student's t-test or chi-square test for quantitative and categorical variables, respectively. Statistical significance was assessed for $\mathrm{p}<0.05$.

\section{Sponsoring}

The Study was sponsored in part by GlaxoSmithKline and all participants were duly informed about this sponsorship and consented for the use of biological samples and data by GlaxoSmithKline and its subsidiaries.

\section{Results}

\section{Recruitment}

A total of 8121 individuals volunteered to participate in the study. Among these subjects, the first 6,738 were invited to attend the clinic and completed the examination. 549 participants $(8.1 \%)$ were not of Caucasian ethnicity and were excluded from the CoLaus study and 6,189 participants met the inclusion criteria (including ethnicity) and were included in the CoLaus study. As the number of subjects who agreed to participate $(8,121)$ was higher than the number of subjects initially planned for the CoLaus study $(6,000), 1,383$ could not be included into the study although they were willing to participate. One subject withdrew after consent due to personal reasons. Overall, the final CoLaus sample $(n=6,188)$ represents $43 \%$ of the eligible responders, $41 \%$ of all the responders and $31 \%$ of the initially sampled population.

The gender and age characteristics of the source population, the initial random sample and the final CoLaus sample are summarized in Table 1. Overall, both the sampled population and the CoLaus study participants were on average one year younger than the base population, due to an under-representation of subjects aged over 65 years while no differences were found for gender distribution.
Further, after excluding non-eligible subjects, no differences were found regarding mean age and gender distribution between the subjects included and the random sample (not shown). The CoLaus Study participants were significantly older $(51.1 \pm 0.1$ vs. $50.8 \pm 0.1$ years, $\mathrm{p}<$ $0.005)$ than the random sample, while no differences were found for gender distribution (not shown). Age at examination of the participants was on average 2 years higher than age at sampling because of the time elapsed between the two procedures. Distribution of the zip codes within the city was comparable between the base population, the random sample and the CoLaus study participants (not shown).

\section{Socio-economic characteristics of the CoLaus study participants}

The CoLaus Study participants' main characteristics are summarized in Table 2. No gender differences were found regarding the percentage of foreigners. Overall, women were more frequently divorced, widowed or single than men and thus were living more often alone or as a monoparental family $(41.7 \%$ vs. $23.6 \%$, p < 0.01$)$. Women were also less frequently on a full-time job, more prone to receive social help $(26.2 \%$ vs. $22.2 \%, \mathrm{p}<0.001)$ and had a lower educational level. Among subjects aged less than 40 years old, $48.4 \%$ of women had a high school/college/ university degree versus $47.4 \%$ of men $(p<0.01)$.

\section{Clinical characteristics of the CoLaus Study participants}

Men had a higher BMI, waist/hip ratio, systolic and DBP levels, but lower body fat percentage, than women. [Table $3]$. Men had higher total cholesterol and triglyceride levels, but lower HDL cholesterol, than women. Fasting blood glucose levels, homocystein, apolipoprotein B, insulin, NT-proBNP and uric acid were higher in men than in women [Tables 3 and 4]. Conversely, women presented higher LDL cholesterol particle size, adiponectin, leptin and hsCRP than men.

Table I: Distribution of participants by age and sex in the source population, the initial random sample and the CoLaus Study participants.

\begin{tabular}{|c|c|c|c|}
\hline & Source population $(n=56,694)$ & Random sample $(n=19,830)$ & CoLaus Study $(n=6,188)$ \\
\hline Women (\%) & $30,14 \mid(53.4)$ & $10,601(53.5)$ & $3,25 \mathrm{I}(52.5)$ \\
\hline$P$ value & & 0.79 & 0.08 \\
\hline Age (years) & $52.0 \pm 11.6$ & $50.8 \pm 11.5$ & $51.1 \pm 10.9$ \\
\hline$P$ value & & $<0.001$ & $<0.001$ \\
\hline \multicolumn{4}{|l|}{ Age group } \\
\hline $35-44$ & $18.877(33.4)$ & $7,265(36.6)$ & $2,051(33.1)$ \\
\hline $45-54$ & $|4,6| 4(25.9)$ & $5,202(26.2)$ & $1,682(27.2)$ \\
\hline $55-64$ & $12.484(22.1)$ & $4,4 I 7(22.3)$ & $1,657(26.8)$ \\
\hline $65-75$ & $10,524(18.6)$ & $2,946(14.9)$ & $798(12.9)$ \\
\hline$P$ value & & $<0.001$ & $<0.001$ \\
\hline
\end{tabular}

Results are expressed as number of subjects and (percentage) or as mean \pm SD. Statistical analysis by Student's t-test or chi-square test compared to the source population 
Table 2: Socio-economic characteristics of the participants in the CoLaus Study.

\begin{tabular}{|c|c|c|c|c|}
\hline & Overall $(n=6,188)$ & Women $(n=3,25 \mathrm{I})$ & Men $(n=2,937)$ & $P$ value \\
\hline Born in Switzerland (\%) & $3,997(64.6)$ & $2,129(65.5)$ & I,868 (63.6) & 0.12 \\
\hline \multicolumn{5}{|l|}{ Marital status (\%) } \\
\hline Single & $1,022(16.5)$ & $569(17.5)$ & $453(15.4)$ & \\
\hline Married & 3,635 (58.8) & $\mathrm{I}, 673(51.5)$ & $1,962(66.9)$ & $<0.001$ \\
\hline Divorced & $1,242(20.1)$ & $761(23.4)$ & $481(16.4)$ & \\
\hline Widowed & $287(4.6)$ & $248(7.6)$ & $39(1.3)$ & \\
\hline \multicolumn{5}{|l|}{ Education (\%) } \\
\hline Basic & I,287 (20.8) & $777(23.9)$ & $510(17.4)$ & \\
\hline Apprenticeship & $2,286(37.0)$ & $1,170(36.0)$ & $1,116(38.0)$ & $<0.001$ \\
\hline High school/college & $\mathrm{I}, 470(23.9)$ & $804(24.8)$ & $666(22.7)$ & \\
\hline University & $1,140(18.4)$ & $497(15.3)$ & $643(21.9)$ & \\
\hline \multicolumn{5}{|l|}{ Work status (\%) } \\
\hline Full time & $3,790(61.2)$ & $\mathrm{I}, 694(52.1)$ & 2,096 (71.4) & $<0.001$ \\
\hline Other & $2,398(38.8)$ & $1,557(47.9)$ & $84 \mid(28.6)$ & \\
\hline
\end{tabular}

Results are expressed as number of subjects and (percentage). Comparison between gender was performed using chi-square test.

Table 3: Clinical characteristics of the participants in the CoLaus study, by gender.

\begin{tabular}{|c|c|c|c|c|}
\hline & Overall $(n=6,188)$ & Women $(n=3,25 \mathrm{I})$ & Men $(n=2,937)$ & $P$ value \\
\hline Age (years) & $53.1 \pm 10.8$ & $53.5 \pm 10.7$ & $52.6 \pm 10.8$ & $<0.001$ \\
\hline Waist/hip ratio & $0.88 \pm 0.08$ & $0.83 \pm 0.07$ & $0.93 \pm 0.06$ & $<0.001$ \\
\hline BMI $\left(\mathrm{kg} / \mathrm{m}^{2}\right)$ & $25.8 \pm 4.6$ & $25.1 \pm 4.9$ & $26.6 \pm 4.0$ & $<0.001$ \\
\hline Body fat (\%) & $29.3 \pm 9.0$ & $34.4 \pm 8.2$ & $23.8 \pm 6.1$ & $<0.001$ \\
\hline Systolic BP (mm Hg) & $128 \pm 18$ & $125 \pm 18$ & $132 \pm 17$ & $<0.001$ \\
\hline Diastolic BP (mm Hg) & $79 \pm 11$ & $78 \pm 11$ & $81 \pm 11$ & $<0.001$ \\
\hline Total cholesterol (mmol/L) & $5.59 \pm 1.04$ & $5.61 \pm 1.03$ & $5.56 \pm 1.04$ & $<0.05$ \\
\hline HDL cholesterol (mmol/L) & $1.63 \pm 0.44$ & $1.81 \pm 0.43$ & $1.44 \pm 0.36$ & $<0.001$ \\
\hline Triglycerides (mmol/L) & $1.40 \pm 1.18$ & $1.16 \pm 0.66$ & $1.66 \pm 1.52$ & $<0.001$ \\
\hline LDL cholesterol particle size $(\mathrm{nm})$ & $272 \pm 4$ & $273 \pm 4$ & $27 I \pm 5$ & $<0.001$ \\
\hline Apolipoprotein B (mg/dL) & $1.74 \pm 1.34$ & $1.69 \pm 1.29$ & $1.80 \pm 1.38$ & $<0.005$ \\
\hline Glucose (mmol/L) & $5.55 \pm 1.15$ & $5.34 \pm 1.02$ & $5.78 \pm 1.23$ & $<0.001$ \\
\hline Insulin $(\mu \mathrm{U} / \mathrm{mL})$ & $8.44 \pm 6.3$ & $7.97 \pm 5.47$ & $9.62 \pm 6.78$ & $<0.001$ \\
\hline Adiponectin $(\mu \mathrm{g} / \mathrm{mL})$ & $9.94 \pm 8.12$ & $12.32 \pm 9.33$ & $7.32 \pm 5.43$ & $<0.001$ \\
\hline Leptin $(\mathrm{ng} / \mathrm{mL})$ & $13.1 \pm 10.7$ & $16.9 \pm 11.7$ & $8.65 \pm 7.3$ & $<0.001$ \\
\hline Homocystein $(\mu \mathrm{mol} / \mathrm{L})$ & $10.4 \pm 4.4$ & $9.4 \pm 3.2$ & $1 \mathrm{I} .4 \pm 5.2$ & $<0.001$ \\
\hline hsCRP (mg/L) & $2.49 \pm 3.48$ & $2.65 \pm 3.71$ & $2.30 \pm 3.21$ & $<0.001$ \\
\hline Pro-BNP (ng/L) & $682 \pm 531$ & $679 \pm 519$ & $686 \pm 545$ & 0.60 \\
\hline
\end{tabular}

Results are expressed as mean \pm SD. BMI: body mass index; HDL: high density lipoprotein, hsCRP: high sensitivity C-reactive protein, BNP: brain natriuretic peptide. Statistical analysis between gender by Student's t-test or chi-square test.

\section{CVRFs within the Colaus study}

More than one third of the overall sample was overweight, and slightly less than one-sixth was obese; overweight and obesity were also more prevalent in men [Table 5] and increased with age. In men aged 35-44 years, the prevalence of overweight and obesity were $40.7 \%$ and $11.4 \%$, respectively, whereas in men aged 65-75 the corresponding figures were $50.8 \%$ and $22.7 \%(\mathrm{p}<0.001)$. The corresponding figures for women were $21.9 \%$ and $9.6 \%$, and $35.8 \%$ and $17.5 \%(\mathrm{p}<0.001)$, respectively.

Smoking was reporter by $27 \%$ of the participants; the prevalence of current smoking was higher in men and tended to decrease with age, from $35.3 \%$ among $35-44$ year olds to $20.7 \%$ among $65-75$ year olds in men ( $\mathrm{p}<$ 0.001 ), the corresponding figures being $28.1 \%$ and $14.7 \%$ in women $(\mathrm{p}<0.001)$. Interestingly, in the $45-54$ age class, prevalence of smoking was higher in women than in men $(30.7 \%$ vs. $28.8 \%(\mathrm{p}<0.001))$.

The prevalence of hypertension was $36.7 \%$ overall, was higher in men and increased with age: $18.3 \%$ and $75.1 \%$ in men aged 35-44 and 65-75, respectively ( $\mathrm{p}<0.001)$; the corresponding numbers in women were $9.9 \%$ and $59.1 \%$ ( $\mathrm{p}<0.001)$. Among hypertensive subjects, 50.1\% were currently taking anti-hypertensive medication. Treat- 
Table 4: Clinical characteristics of the participants of the CoLaus study, by gender.

\begin{tabular}{|c|c|c|c|c|}
\hline & Overall $(n=6,188)$ & Women $(n=3,25 \mathrm{I})$ & Men $(n=2,937)$ & $P$ value \\
\hline ASAT (U/L) & $29.96 \pm 14.04$ & $26.22 \pm 9.88$ & $34.10 \pm 16.57$ & $<0.001$ \\
\hline ALAT (U/L) & $27.84 \pm 19.50$ & $21.98 \pm 14.47$ & $34.32 \pm 22.13$ & $<0.001$ \\
\hline Alkaline phosphatase (U/L) & $63.47 \pm 20.72$ & $62.66 \pm 20.99$ & $64.38 \pm 20.38$ & $<0.001$ \\
\hline Gamma-GT (U/L) & $33.20 \pm 59.04$ & $22.95 \pm 25.78$ & $44.57 \pm 79.80$ & $<0.001$ \\
\hline Calcium (mmol/L) & $2.29 \pm 0.09$ & $2.28 \pm 0.10$ & $2.29 \pm 0.09$ & $<0.001$ \\
\hline Albumin $(g / L)$ & $44.20 \pm 2.53$ & $43.73 \pm 2.48$ & $44.71 \pm 2.48$ & $<0.001$ \\
\hline Total protein $(\mathrm{g} / \mathrm{L})$ & $74.41 \pm 4.39$ & $73.93 \pm 4.42$ & $74.95 \pm 4.30$ & $<0.001$ \\
\hline Uric acid $(\mu \mathrm{mol} / \mathrm{L})$ & $313.49 \pm 84.47$ & $270.56 \pm 67.23$ & $361.08 \pm 75.69$ & $<0.001$ \\
\hline CDT (\% of total transferrin) & $0.95 \pm 0.81$ & $0.80 \pm 0.48$ & $1.12 \pm 1.02$ & $<0.001$ \\
\hline
\end{tabular}

Results are expressed as mean \pm SD. ASAT: Aspartate amino-transferase. ALAT: Alanine amino-transferase. Gamma-GT: Gamma-glutaryltransferase. CDT: Carbohydrate deficient transferrin. Statistical analysis between genders by Student's t-test or chi-square test.

Table 5: Prevalence of selected cardiovascular risk factors in the participants of the CoLaus study.

\begin{tabular}{|c|c|c|c|c|}
\hline & Overall $(n=6,188)$ & Women $(n=3,25 \mathrm{I})$ & Men $(n=2,937)$ & $P$ value \\
\hline \multicolumn{5}{|l|}{ BMI status (\%) } \\
\hline Overweight & $2265(36.6)$ & $922(28.4)$ & 1343 (45.7) & $<0.001$ \\
\hline Obesity & 974 (I5.7) & $472(14.5)$ & $502(17.1)$ & \\
\hline \multicolumn{5}{|l|}{ Smoking status (\%) } \\
\hline Current & $1673(27.0)$ & $813(25.0)$ & $860(29.3)$ & \\
\hline Former & 2034 (32.9) & $904(27.8)$ & $1130(38.5)$ & $<0.001$ \\
\hline Never & $2479(40.1)$ & $1534(47.2)$ & $945(32.2)$ & \\
\hline \multicolumn{5}{|c|}{ Blood pressure status (\%) } \\
\hline Hypertension & $2268(36.7)$ & $1004(30.9)$ & $1264(43.0)$ & $<0.001$ \\
\hline Treated hypertension & $1|3|(50.1)$ & $537(53.8)$ & $594(47.1)$ & $<0.005$ \\
\hline Treated to goal & $542(48.0)$ & $27 I(50.6)$ & $27 I(45.6)$ & NS \\
\hline \multicolumn{5}{|l|}{ Lipid status (\%) } \\
\hline High LDL cholesterol & $1263(20.8)$ & $631(19.5)$ & $632(22.2)$ & $<0.001$ \\
\hline High triglycerides & $773(12.5)$ & $216(6.7)$ & $557(19.0)$ & $<0.001$ \\
\hline Low HDL cholesterol & $170(2.8)$ & $35(1.1)$ & $135(4.6)$ & $<0.001$ \\
\hline High HDL cholesterol & $3296(53.4)$ & $2324(71.6)$ & $972(33.2)$ & $<0.001$ \\
\hline Dyslipidemia & $2113(34.2)$ & $862(26.6)$ & $|25|(42.7)$ & $<0.001$ \\
\hline Treated dyslipidemia & $286(13.5)$ & $95(11.0)$ & $191(15.3)$ & $<0.001$ \\
\hline \multicolumn{5}{|l|}{ Glycaemic status (\%) } \\
\hline Diabetes & $407(6.6)$ & $130(4.0)$ & $277(9.5)$ & $<0.001$ \\
\hline Known Diabetes & $270(66.3)$ & $89(68.5)$ & $|8|(65.3)$ & $<0.005$ \\
\hline Treated Diabetes & $260(96.3)$ & $85(95.5)$ & $175(96.7)$ & $<0.01$ \\
\hline Microalbuminuria (\%) & $380(6.3)$ & $173(5.4)$ & $207(7.3)$ & \\
\hline
\end{tabular}

Overweight: $\mathrm{BMI} \geq 25 \mathrm{~kg} / \mathrm{m}^{2}$. Obesity: $\mathrm{BMI} \geq 30 \mathrm{~kg} / \mathrm{m}^{2}$. Hypertension: Blood pressure $\geq 140 / 90 \mathrm{mmHg}$ and/or presence of anti-hypertensive drug treatment. Low HDL cholesterol: $<1 \mathrm{mmol} / \mathrm{L}$; high HDL cholesterol: $\geq 1.6 \mathrm{mmol} / \mathrm{L}$; high LDL cholesterol: $\geq 4.1 \mathrm{mmol} / \mathrm{L}$ and high triglyceride: $\geq 2.2 \mathrm{mmol} / \mathrm{L}$. Dyslipidemia: low HDL cholesterol and/or high triglyceride and/or $\mathrm{LDL}$ cholesterol $\geq 4.1 \mathrm{mmol} / \mathrm{L}$ or $\geq 2.6 \mathrm{mmol} / \mathrm{L}$ in presence of self-reported myocardial infarction, stroke, coronary artery disease or diabetes. Diabetes: fasting plasma glucose $\geq 7 \mathrm{mmol} / \mathrm{L}$ and/or presence of oral hypoglycaemic or insulin treatment. Microalbuminuria :albumin-to-creatinine ratio $>30 \mathrm{mg} / \mathrm{g}$

ment for hypertension was more frequent in female subjects and increased with age (from $32.2 \%$ to $59.4 \%$ ). Of the treated hypertensive subjects more than half $(52.0 \%)$ had BP levels $\geq 140 / 90 \mathrm{mmHg}$.

High LDL cholesterol, high triglyceride and low HDL cholesterol levels were seen in $20.8 \%, 12.5 \%$ and $2.8 \%$ of the subjects, respectively and these conditions were also more prevalent in men. The prevalence of high HDL cholesterol was $53.4 \%$ and higher in women than men $(71.6 \%$ vs. $33.2 \%)$. Overall, one third of the sample had dyslipi- demia, the prevalence of which was higher in men $(42.7 \%)$ than in women $(26.6 \%)$.

Use of statin therapy in subjects with high LDL cholesterol was $5.6 \%$. Prevalence of statin therapy was $69 \%$ in subjects after myocardial infarction, 33\% in subjects after stroke and $70 \%$ in subjects after coronary artery bypass graft. Target level of LDL-cholesterol for secondary prevention, as recommended $(<2.6 \mathrm{mmol} / \mathrm{l})$, was achieved in $28 \%, 38 \%, 28 \%$ and $33 \%$ of the subjects with diabetes, 
myocardial infarction, stroke and coronary artery bypass graft, respectively.

The overall prevalence of diabetes was $6.6 \%$, and was higher in men. Nine subjects $(2.2 \%)$ reported to have T1DM. The prevalence of diabetes increased with age, from $2.5 \%$ to $17.2 \%$ in men aged $35-44$ and $65-75$, respectively; the corresponding numbers were $1.2 \%$ and $9.0 \%$ in women with a peak prevalence of $17.2 \%$ in men aged $>65$. Roughly a third were newly diagnosed diabetics (31.5\% for women and $34.7 \%$ for men, respectively). The prevalence of IFG in the CoLaus population was $9.8 \%$ and was higher in men than in women (14.3\% vs. $5.6 \%)$.

Treatment for diabetes was present in $73.9 \%$ of diabetic subjects but nearly all known diabetics were treated $(96.3 \%)$. Of the treated diabetic subjects $63.9 \%$ had a fasting blood glucose $\geq 7 \mathrm{mmol} / \mathrm{L}$, at the time of their visit.

Finally, $0.7 \%$ of women and $2.6 \%$ of men reported a personal history of myocardial infarction $(p<0.001)$; conversely, no gender differences were found regarding personal history of stroke: $1.0 \%$ of women vs. $1.3 \%$ of men, $\mathrm{p}=0.16$.

\section{Power estimates}

The power of the CoLaus study for an unmatched casecontrol design to study genotype/phenotype associations depends on the number of cases/controls and estimated effect size [Figure 2]. For hypertension with 2268 cases, the estimated power is 0.9 for a 1.4 effect size and 0.5 for a 1.3 effect size. Cases for main CVRFs in the CoLaus study are: dyslipidemia: 2021, obesity: 974, smoking (> 25 cigarettes/day): 746, Type 2 diabetes: 398, coronary heart disease: 262, low HDL: 170. For continuous trait analysis, the example of SBP was taken [Figure 3]. For allelic frequencies of 0.2 to 0.4 , the study has an estimated power of $>0.8$ to detect BP variations of $2.0-2.3 \mathrm{~mm} \mathrm{Hg}$.

\section{Discussion}

Described in this report are the rationale, objectives, methods and first results from the CoLaus study, a singlecenter population-based sample including 6188 extensively phenotyped Caucasian subjects aged 35-75. Our results indicate that the prevalence of major CVRFs is high, in particular in men. In addition, this collection represents a powerful tool to identify new molecular determinants of CVRFs and associated diseases [17].

The participation rate of $41 \%$ in the CoLaus study is comparable to the MONICA surveys conducted in Switzerland and in France [18]. The lower response rate among elderly subjects is in agreement with previous data [19] and might be related to a lower interest for the study. However, the distribution of age groups 35-54 and 55-75 in the CoLaus study was comparable to the source population [Table 1]. Also, there was no gender or zip code distribution difference between the source population, the random sample and the CoLaus participants. Although the optimal sampling frame would have consisted of a list of all Caucasians living in the city, information on ethnicity was not available to the investigators before examination and it is not possible to assess whether ethnicity had an effect on the participation rate.

The prevalence of main CVRFs was high in the CoLaus participants. Roughly over half of the participants presented with overweight and obesity, over a third had high BP or dyslipidemia while one in 15 participants had diabetes.

In agreement with the literature [20], men had a higher prevalence of obesity and overweight than women. Further, comparison with data from the MONICA study suggests that the prevalence of obesity is increasing, which confirms what has been found in the nearby city of Geneva [21]. Compared to data from the National Health Examination Survey (NHANES) in the United States (1999-2004), the prevalence of obesity remains lower in Lausanne[22]. The higher prevalence of overweight in men might also account for their higher prevalence of diabetes and hypertension. In clinical practice, the diagnosis of hypertension relies on several consecutive BP measurements but as in most epidemiological studies, BP measurements were conducted during a single visit [23]. Terminal digit preference in BP readings may induce a bias, a consistency check was conducted showing no significant deviation of terminal digit frequency from the $10 \%$ value for all $\mathrm{BP}$ measurements (not shown). The prevalence of hypertension was higher in men than in women and increased with age. Interestingly, the genderspecific prevalence rates found in the CoLaus study were similar to those previously reported for the same age group in Italy [24] and in nearby Geneva [21]. We also observed that over half of the treated hypertensive subjects had a $\mathrm{BP} \geq 140 / 90 \mathrm{mmHg}$ at the time of their examination, indicating the continuous need to improve treatment compliance. The prevalence of diabetes was $6.6 \%$ and was significantly higher in men and in particular after the age of 55 years. These numbers are similar to other Swiss estimates [25] and to the KORA Augsburg study in the southern part of Germany [26]. About a quarter of the CoLaus participants were smokers, a figure quite similar to the data reported for the Geneva population in 2003 [21] and somewhat lower than those observed in the USA[27]. The prevalence of smoking was higher in men than in women, although this difference tended to decrease among younger age groups, as previously reported [28]. Indeed, in the age group 45-54, the prevalence of smoking was higher in women than in men, sug- 
Additive mode of action

$\mathrm{N}=5500$

$P$ value $=10^{-7}$

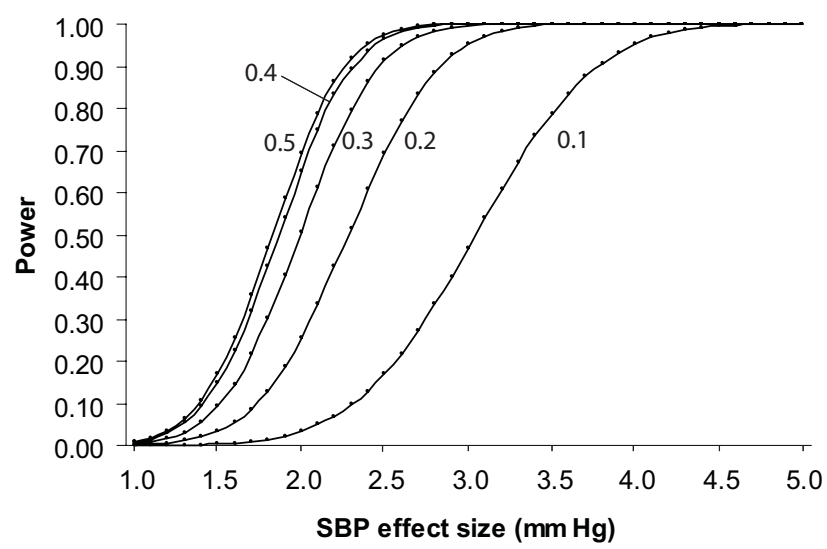

Figure 2

Power estimates for the CoLaus study. Power for various sample sizes in unmatched case-control studies. Arbitrary allelic frequency of 0.3 , a disease prevalence of $50 \%$ and a type I error rate of $10^{-7}$ taking into account 500 '000 genetics markers. Curves are for estimated genetic effects (odds ratios) of I.2 to I.8. The numbers of cases for main CVRFs in the CoLaus study are: Hypertension: 2268. Dyslipidemia: 2021. Obesity: 963. Smoking (> 25 cigarettes/ day): 746. Type 2 diabetes: 398. Coronary heart disease: 262. Low HDL: 170.

gesting that the "gender gap" regarding smoking no longer exists for middle-aged subjects.

The high prevalence of CVRFs in this study population underscores the necessity to increase disease awareness, to improve screening in high risk subjects and to promote prevention both at the public health and individual level.

Recently, an increasing number of reports have demonstrated the power of whole genome association studies approach in complex diseases such as diabetes [29], obesity [30] and cardiovascular disease [31]. The size of the CoLaus study, the population-based design and the indepth phenotypisation were chosen in order to harness the power of this technology using dichotomous and continuous trait analyses. In particular, this ensures an identical phenotypisation in cases and controls, which has been a limitation in some of the recently published reports [32] and allows to study complex traits such as the metabolic syndrome. Combined analysis of our results with other datasets has already allowed to identify new genetic determinants associated with circulating LDL-plasma levels [17] (similar results were published concomitantly by other groups $[33,34]$ ) and determinants associated with height [35]. Additional analysis are currently ongoing.
Disease prevalence $50 \%$

Minor allele frequency 0.30 , type 1 error rate $10^{-7}$

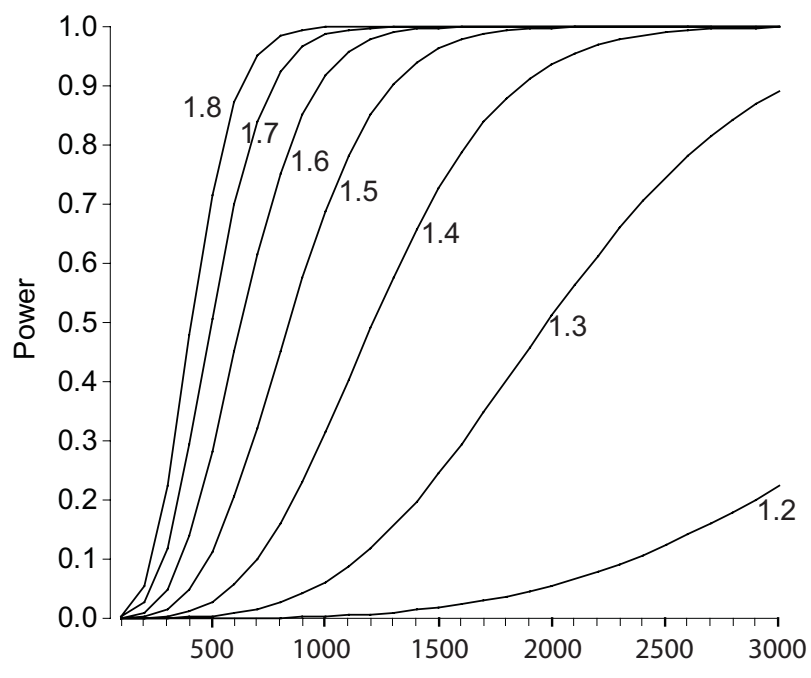

Number of cases

\section{Figure 3}

Power estimates for the CoLaus study. Power for the analysis of systolic blood pressure as a continuous variable. Power calculations using a continuous outcome for independent subjects, with an additive mode of action for the allele and a type I error rate of $10^{-7}$. Calculations were done for various minor allele frequencies $(0.1$ to 0.5$)$.

\section{Perspectives}

A more comprehensive characterization of the Colaus participants is currently ongoing. First all participants aged 35 to 65 were solicited to undergo a psychiatric investigation based on a semi-structured diagnostic interview. In addition, 500 subjects were assessed for CV functional measurements. Indeed several previous studies have revealed associations between mood disorders and, in particular depression, and CVRFs and CV diseases (reviewed in [36]). The availability of a simultaneous $\mathrm{CV}$ and psychiatric phenotype will allow us to further explore the epidemiologic and potentially a genetic basis for this association. Finally, 500 randomly selected non-diabetic individuals underwent a 2 hour glucose tolerance test. The results from these investigations will be reported separately.

A longitudinal follow-up of all participants in the CoLaus study is planned and shall provide essential data for trends over time of major CVRFs and on incident cases of $\mathrm{CV}$ diseases. In the current cross-sectional study, participants were asked whether they consented to be contacted for follow-up, with $>90 \%$ favorable responses.

\section{Conclusion}

In summary, these initial results from the CoLaus study show that the prevalence of main CVRFs is high in the 
Caucasian population of Lausanne, and in particular in men. This emphasizes the need for continued epidemiological monitoring and for strengthening interventions to reduce the prevalence and severity of CVRFs in this population. This population-based study with over 6000 extensively characterized and genotyped participants constitutes a unique resource to identify new or replicate suspected or known molecular determinants of CVRFs and associated diseases.

\section{Abbreviations}

$\mathrm{CV}$ : cardiovascular; CVD: cardiovascular disase; CVRF: cardiovascular risk factor; BP: blood pressure; SBP: systolic blood pressure, DBP: diastolic blood pressure; BMI: body mass index; LDL-cholesterol: low-density cholesterol; HDL-cholesterol: high density cholesterol; NHANES: National Health and Nutrition Survey; NT-proBNP: N-terminal pro-Brain Natriuretic Peptide; ASAT: aspartate aminotrasnferase; ALAT: alanine aminotransferase; GammaGT: gamma glutaryl transferase; CDT: carbohydrate deficient transferine; hs CRP: high sensitivity C-reactive protein. CAD: coronary artery disease, T1DM/T2DM: Type 1/ Type 2 diabetes mellitus.

\section{Competing interests}

Kijoung S. Song, Xin Yuan, Theodore M. Danoff, Heide A. Stirnadel, Dawn Waterworthand Vincent Mooser are fulltime employees of GlaxoSmithkline.

\section{Authors' contributions}

$\mathrm{MF}, \mathrm{VM}, \mathrm{PV}, \mathrm{GW}, \mathrm{AP}, \mathrm{DH}, \mathrm{FP}$ contributed to the provision of participants and study material. PV, GW, VM, DW, HS, $\mathrm{TD}, \mathrm{FP}, \mathrm{DH}$ and MP participated in the study design and conception and the coordination of the project. MF, VM, $\mathrm{PMV}, \mathrm{MB}, \mathrm{KS}, \mathrm{XY}$ assembled the data and performed the statistical analyses. PV, MF, VM, DW, HS, PMV analyzed and interpreted the data. PV, MF, PMV drafted the article which was revised by VM, VM, MB, MP and GW. All authors read and approved the final manuscript.

\section{Additional material}

\section{Additional file 1}

Clinical chemistry and biological makers measured in the CoLaus study. Analytical procedures, maximum inter and intra-batch coefficient of variation and manufacturers for the Clinical chemistry and biological makers measured in the CoLaus study.

Click here for file

[http://www.biomedcentral.com/content/supplementary/14712261-8-6-S1.doc]

\section{Acknowledgements}

The CoLaus study was supported by research grants from GlaxoSmithKline and from the Faculty of Biology and Medicine of Lausanne, Switzerland.
The authors would like to express their gratitude to the participants in the Lausanne Colaus study, to the investigators who have contributed to the recruitment, in particular Yolande Barreau, Anne-Lise Bastian, Binasa Ramic, Martine Moranville, Martine Baumer, Marcy Sagette, Jeanne Ecoffey and Sylvie Mermoud for data collection, and to Allen Roses, Lefkos T. Middleton and Paul Matthews for their support.

\section{References}

I. Mathers CD, Loncar D: Projections of global mortality and burden of disease from 2002 to 2030. PLoS Med 2006, 3:e442.

2. Caulfield M, Munroe P, Pembroke J, Samani N, Dominiczak A, Brown M, Benjamin N, Webster J, Ratcliffe P, O'Shea S, Papp J, Taylor E, Dobson R, Knight J, Newhouse S, Hooper J, Lee W, Brain N, Clayton D, Lathrop GM, Farrall M, Connell J: Genome-wide mapping of human loci for essential hypertension. The Lancet 2003, 36 I (9375):2I I8-2I 23.

3. Rankinen T, Zuberi A, Chagnon YC, Weisnagel SJ, Argyropoulos G, Walts $B$, Perusse L, Bouchard C: The human obesity gene map: the 2005 update. Obesity 2006, 14:529-644.

4. Romeo S, Pennacchio LA, Fu Y, Boerwinkle E, Tybjaerg-Hansen A, Hobbs $\mathrm{HH}$, Cohen JC: Population-based resequencing of ANGPTL4 uncovers variations that reduce triglycerides and increase HDL. Nat Genet 2007, 39:513-516.

5. Chanock SJ, Manolio T, Boehnke M, Boerwinkle E, Hunter DJ, Thomas G, Hirschhorn JN, Abecasis G, Altshuler D, Bailey-Wilson JE, Brooks LD, Cardon LR, Daly M, Donnelly P, Fraumeni JF Jr., Freimer NB, Gerhard DS, Gunter C, Guttmacher AE, Guyer MS, Harris EL, Hoh J, Hoover R, Kong CA, Merikangas KR, Morton CC, Palmer LJ, Phimister EG, Rice JP, Roberts J, Rotimi C, Tucker MA, Vogan KJ, Wacholder S, Wijsman EM, Winn DM, Collins FS: Replicating genotype-phenotype associations. Nature 2007, 447:655-660.

6. City of Lausanne population registry: (data for 2003) 2008 [http://www.lausanne.ch/view.asp?Domld=63584].

7. Worsley A, Gribbin CC: A factor analytic study on the twelve item general health questionnaire. Aust N Z J Psychiatry 1977, I I:260-272.

8. Folstein MF, Folstein SE, McHugh PR: "Mini-mental state". A practical method for grading the cognitive state of patients for the clinician. J Psychiatr Res 1975, I 2: I89- I98.

9. El Assaad MA, Topouchian JA, Darne BM, Asmar RG: Validation of the Omron HEM-907 device for blood pressure measurement. Blood Press Monitoring 2002, 7(4):237-24I.

10. Lean ME, Han TS, Morrison CE: Waist circumference as a measure for indicating need for weight management. Brit Med J 1995, 3 I I: I58-16I.

II. Jebb SA, Siervo M, Murgatroyd PR, Evans S, Fruhbeck G, Prentice AM: Validity of the leg-to-leg bioimpedance to estimate changes in body fat during weight loss and regain in overweight women: a comparison with multi-compartment models. Int J Obes (Lond) 2007, 3 I:756-762.

12. Hamilton JB: Patterned loss of hair in man; types and incidence. Ann N Y Acad Sci 195I, 53:708-728.

13. Third Report of the National Cholesterol Education Program (NCEP) Expert Panel on Detection, Evaluation, and Treatment of High Blood Cholesterol in Adults (Adult Treatment Panel III) final report. Circulation 2002, I 06:3143-342I.

14. Alberti KG, Zimmet PZ: Definition, diagnosis and classification of diabetes mellitus and its complications. Part I: diagnosis and classification of diabetes mellitus provisional report of a WHO consultation. Diabet Med 1998, I5:539-553.

I5. Gauderman WJ, Morrison JM: QUANTO I.I. A computer program for power and sample size calculations for genetic-epidemiologic studies. 2006 [http://hydra.usc.edu/gxe/].

16. Wietlisbach V, Paccaud F, Rickenbach M, Gutzwiller F: Trends in cardiovascular risk factors (1984-1993) in a Swiss region: results of three population surveys. Prev Med I997, 26:523-533.

17. Sandhu MS, Waterworth DM, Debenham SL, Wheeler E, Papadakis K, Zhao JH, Song K, Yuan X, Johnson T, Ashford S, Inouye M, Luben R, Sims M, Hadley D, McArdle W, Barter P, Kesaniemi YA, Mahley RW, McPherson R, Grundy SM, Bingham SA, Khaw KT, Loos RJ, Waeber G, Barroso I, Strachan DP, Deloukas P, Vollenweider P, Wareham NJ, Mooser V: LDL-cholesterol concentrations: a genome-wide association study. Lancet 2008, 37 I:483-49I. 
18. Wolf HK, Kuulasmaa K, Tolonen H, Ruokokoski E: Participation rates, quality of sampling frames and sampling fractions in the MONICA surveys. 1998 [http://www.ktl.fi/publications/mon ica/nonres/nonres.htm]. Helsinki, Finland, WHO MONICA

19. Groves RM, Couper M: Nonresponse in household interview surveys New York, John Wiley \& Sons, Inc.; 1998: I-368.

20. Schokker DF, Visscher TL, Nooyens AC, van Baak MA, Seidell JC: Prevalence of overweight and obesity in the Netherlands. Obes Rev 2007, 8: I0I-107.

21. Galobardes B, Costanza MC, Bernstein MS, Delhumeau CH, Morabia A: Trends in risk factors for the major "lifestyle-related diseases" in Geneva, Switzerland, 1993-2000. Ann Epidemiol 2003. 1 3:537-540.

22. Ogden CL, Carroll MD, Curtin LR, McDowell MA, Tabak CJ, Flegal $\mathrm{KM}$ : Prevalence of overweight and obesity in the United States, 1999-2004. JAMA 2006, 295:I549-1555.

23. Wolf-Maier K, Cooper RS, Banegas JR, Giampaoli S, Hense HW, Joffres $M$, Kastarinen M, Poulter N, Primatesta $P$, Rodriguez-Artalejo $F$ Stegmayr B, Thamm M, Tuomilehto J, Vanuzzo D, Vescio F: Hypertension prevalence and blood pressure levels in 6 European countries, Canada, and the United States. JAMA 2003, 289:2363-2369.

24. Giampaoli S, Palmieri L, Dima F, Pilotto L, Vescio MF, Vanuzzo D Socioeconomic aspects and cardiovascular risk factors: experience at the Cardiovascular Epidemiologic Observatory [Italian]. Ital Heart J Suppl 200I, 2:294-302.

25. Nedeltchev K, Arnold M, Baumgartner R, Devuyst G, Erne P, Hayoz $D$, Sztajzel R, Tettenborn B, Mattle HP: Vascular risk factors in the Swiss population. J Neurol 2005, 252:1210-1216.

26. Herder C, Illig T, Rathmann W, Martin S, Haastert B, Muller-Scholze S, Holle R, Thorand B, Koenig W, Wichmann HE, Kolb H: Inflammation and type 2 diabetes: results from KORA Augsburg. Gesundheitswesen 2005, 67 Suppl I:SI I5-SI2I.

27. Cowie CC, Rust KF, Byrd-Holt DD, Eberhardt MS, Flegal KM, Engelgau MM, Saydah SH, Williams DE, Geiss LS, Gregg EW: Prevalence of diabetes and impaired fasting glucose in adults in the U.S. population: National Health And Nutrition Examination Survey 1999-2002. Diabetes Care 2006, 29:1263-1268.

28. Chiolero A, Wietlisbach V, Ruffieux C, Paccaud F, Cornuz J: Clustering of risk behaviors with cigarette consumption: $A$ population-based survey. Prev Med 2006, 42:348-353.

29. Scott LJ, Mohlke KL, Bonnycastle LL, Willer CJ, Li Y, Duren WL, Erdos MR, Stringham HM, Chines PS, Jackson AU, Prokunina-Olsson L, Ding CJ, Swift AJ, Narisu N, Hu T, Pruim R, Xiao R, Li XY, Conneely KN, Riebow NL, Sprau AG, Tong M, White PP, Hetrick KN, Barnhart MW, Bark CW, Goldstein JL, Watkins L, Xiang F, Saramies J, Buchanan TA, Watanabe RM, Valle TT, Kinnunen L, Abecasis GR, Pugh EW, Doheny KF, Bergman RN, Tuomilehto J, Collins FS, Boehnke M: A genome-wide association study of type 2 diabetes in Finns detects multiple susceptibility variants. Science 2007, 3 16:134I-I345.

30. Frayling TM, Timpson NJ, Weedon MN, Zeggini E, Freathy RM, Lindgren CM, Perry JR, Elliott KS, Lango H, Rayner NW, Shields B, Harries LW, Barrett JC, Ellard S, Groves C], Knight B, Patch AM, Ness AR, Ebrahim S, Lawlor DA, Ring SM, Ben-Shlomo Y, Jarvelin MR, Sovio U, Bennett AJ, Melzer D, Ferrucci L, Loos RJ, Barroso I, Wareham NJ, Karpe F, Owen KR, Cardon LR, Walker M, Hitman GA, Palmer CN, Doney AS, Morris AD, Smith GD, Hattersley AT, McCarthy MI: A common variant in the FTO gene is associated with body mass index and predisposes to childhood and adult obesity. Science 2007, 3 16:889-894.

31. McPherson R, Pertsemlidis A, Kavaslar N, Stewart A, Roberts R, Cox DR, Hinds DA, Pennacchio LA, Tybjaerg-Hansen A, Folsom AR, Boerwinkle $\mathrm{E}$, Hobbs $\mathrm{HH}$, Cohen JC: A common allele on chromosome 9 associated with coronary heart disease. Science 2007, 316:1488-1491.

32. Genome-wide association study of 14,000 cases of seven common diseases and 3,000 shared controls. Nature 2007, 447:66I-678.

33. Willer C], Sanna S, Jackson AU, Scuteri A, Bonnycastle LL, Clarke R, Heath SC, Timpson NJ, Najjar SS, Stringham HM, Strait J, Duren WL, Maschio A, Busonero F, Mulas A, Albai G, Swift Al, Morken MA, Narisu N, Bennett D, Parish S, Shen H, Galan P, Meneton P, Hercberg S, Zelenika D, Chen WM, Li Y, Scott LJ, Scheet PA, Sundvall J, Watanabe RM, Nagaraja R, Ebrahim S, Lawlor DA, Ben-Shlomo Y, vey-Smith G, Shuldiner AR, Collins R, Bergman RN, Uda M, Tuomilehto J, Cao A,
Collins FS, Lakatta E, Lathrop GM, Boehnke M, Schlessinger D, Mohlke KL, Abecasis GR: Newly identified loci that influence lipid concentrations and risk of coronary artery disease. Nat Genet 2008, 40:161-169.

34. Wallace C, Newhouse SJ, Braund P, Zhang F, Tobin M, Falchi M, Ahmadi K, Dobson RJ, Marcano AC, Hajat C, Burton P, Deloukas P, Brown M, Connell JM, Dominiczak A, Lathrop GM, Webster J, Farrall M, Spector T, Samani NJ, Caulfield MJ, Munroe PB: Genome-wide association study identifies genes for biomarkers of cardiovascular disease: serum urate and dyslipidemia. Am J Hum Genet 2008, 82:139-149.

35. MN W, H L, CM L C W, Evans DM, M M, RM F, JRB P, S S, AS H, Samani NJ, B S, P P, M F, A D, Initiative DG, The Wellcome Trust Case Control Consortium, T J, S B, JS B, P V, DM W, V M, CN P, AD M, WH O, Consortium CGEM, M C, Munroe PB, Hattersley AT, McCarthy MI, TM F: Genome-wide association analysis identifies 20 loci that influence adult height. Nat Genet 2008.

36. Musselman DL, Evans DL, Nemeroff CB: The relationship of depression to cardiovascular disease: epidemiology, biology, and treatment. Arch Gen Psychiatry 1998, 55:580-592

\section{Pre-publication history}

The pre-publication history for this paper can be accessed here:

http://www.biomedcentral.com/1471-2261/8/6/prepub

Publish with Biomed Central and every scientist can read your work free of charge

"BioMed Central will be the most significant development for disseminating the results of biomedical research in our lifetime. "

Sir Paul Nurse, Cancer Research UK

Your research papers will be:

- available free of charge to the entire biomedical community

- peer reviewed and published immediately upon acceptance

- cited in PubMed and archived on PubMed Central

- yours - you keep the copyright
BioMedcentral 